\title{
Methodological Considerations in Employing the Continuous Discourse Tracking Procedure with Hearing-Impaired Adults
}

\author{
L. le Roux, BA (Pretoria) \\ Department of Speech Pathology and Audiology, \\ University of the Witwatersrand, Johannesburg \\ R.W. Turton, MA (Witwatersrand) \\ Department of Psychology, \\ University of the Witwatersrand, Johannesburg
}

\begin{abstract}
This article addresses the various methodological issues involved in the use of the Continuous Discourse Tracking (CDT) procedure as a test instrument for evaluating communication efficiency in hearing-impaired adults. An overview of the potentially confounding variables associated with the CDT technique is provided and consideration is given to the reliability of this procedure with reference to areas requiring systematic investigation. It is proposed that the adoption of an alternative paradigm as well as interdisciplinary approach to test construction may facilitate a multi-dimensional perspective to the assessment of speechreading and communicative ability in the hearing-impaired population.
\end{abstract}

\section{OPSOMMING}

Hierdie artikel bespreek die verskillende metodologiese aspckte inherent a an die gebruik van die "Continuous Discourse Tracking" prosedure as 'n meetinstrument by die evaluering van kommunikasie-effektiwiteit by gehoorgestremde volwassenes. 'n Teoretiese oorsig van die moontlike kontaminerende veranderlikes wat met hierdie tegniek gepaard gaan, word verskaf. Vervolgens word die betroubaarheid van hierdie instrument indringend beskou met verwysing na navorsingsareas wat sistematiese ondersoek verg. Daar word voorgestel dat die aanvaarding van 'n alternatiewe pa radigma sowel as interdissiplinêre pogings wat betref toetskonstruksie, 'n multidimensionele benadering tot die evaluasie van spraaklees- en kommunikasievermoëns by gehoorgestremdes kan bevorder.

\section{INTRODUCTION}

Recent advanced technology has introduced a new era in intervention strategies with profoundly hearing-impaired individuáls, particularly for those postlingually deafened. South Africa has recently inaugurated a multi-disciplinary approach to the assessment and rehabilitation of these individuals (Müller, 1988) which has sparked off general interest in the potential benefits of cochlear implants in particular.

For the audiologist, whose role is crucial, these developments present exciting challenges. The, profession is increasingly called upon not only to assess candidates for cochlear prostheses, but also to recommend suitable alternatives, document the effectiveness of sensory devices and to provide for essential after-care services.

These considerations, coupled with the current focus on quality assurance in clinical practice, emphasize the importance of accurate measurement of speech communication in the profoundly hearing-impaired. In addition, there is an urgent need to adapt currently available test instruments and to construct test stimuli to meet local demands for culturally appropriate diagnostic tools.

The objective of this paper is to consider critically one of the speechreading assessment techniques, namely the Continuous Discourse Tracking Procedure, which has been widely applied to the assessment and treatment of postlingually, profoundly hearing-impaired persons. An appreciation of this technique is essential in order to avoid mechanical application of this procedure and to encourage clinicians to become discerning test users.

\section{THE ASSESSMENT OF SPEECHREADING ABILITY}

In reviewing the literature on speechreading assessment it is notable that, despite the absence of a conclusive theoretical framework for speech information processing, many innovative and radically different approaches have appeared during the last decade (e.g. Boothroyd, 1987 (cited in Montgomery \& Demorest, 1988); Cronin, 1979; Middelweerd \& Plomp, 1987).

The absence of a viable model of speech perception has, nevertheless, exerted a noticeable influence on the standard of speechreading instruments developed so far; Montgomery \& Demorest (1988) view most of these as being of inferior quality and describe them as not meeting current psychometric requirements. This statement needs some qualification however; it pertains specifically to the insufficient availability of psychometric data on existing measures, rather than to the inadequacy of the instruments per se.

Fortunately, as a result of several developments, most researchers are positive about improvements in the standard of speechreading instruments. They base their optimism on the following: 


\section{A LEGACY \\ OF SOUNDADVICE \\ AND EQUIPMENT}

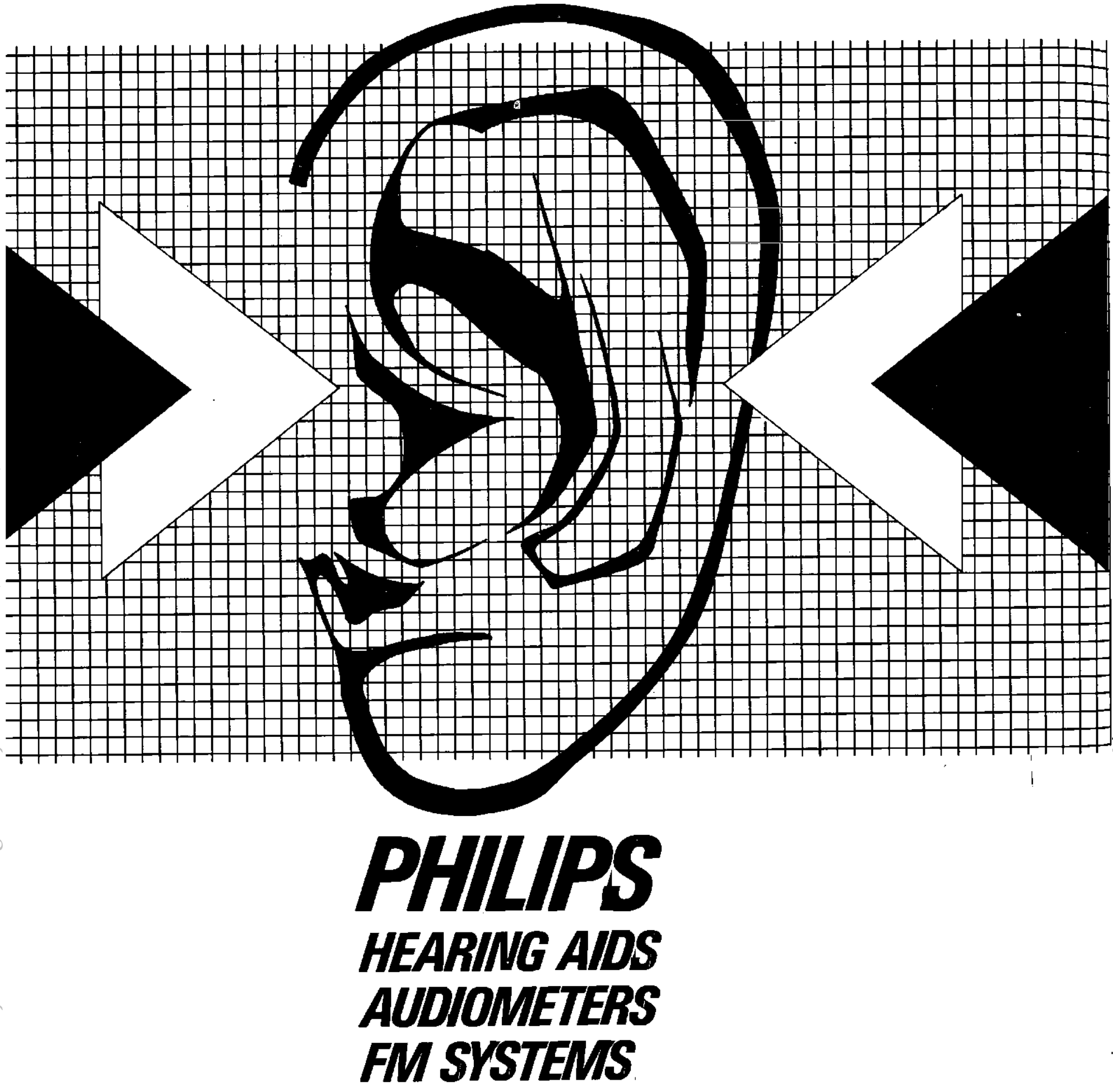

Head Office: 1005 Cavendish Chambers, 183 Jeppe Street

P.O. Box 3069, Johannesburg 2000. Tel: (011) 337-7537. 
1) the recent strides which have been made in terms of model development (Massaro, 1987);

2) the advent of interactive videodisc technology which has opened up avenues for exploring new methods of testing and

3) the availability of test construction and evaluation techniques which hopefully will be increasingly used by experimenters in this field during the stages of test development.

At present, however, it is generally agreed that the researcherclinician who strives to evaluate an individual's speechreading performance in a reliable manner, is confronted with an extremely complex task.

\section{THE CONNECTED DISCOURSE TRACKING (CDT) PROCEDURE}

One unique and highly versatile procedure which represents an alternative aproach to the measurement of speechreading skills in the hearing-impaired, is the CDT procedure, originally described by De Filippo and Scott (1978). Tracking is a timed technique in which the talker (sender.) reads from a prepared text presented in a phrase-by-phrase manner. The receiver "listens" to each successive group of words as an entity, before repeating verbatim what the sender has said. If the receiver is correct, the talker proceeds to the next segment: if an error occurs in the repetition of the material, the talker and receiver employ various strategies to elicit a verbatim response. The goal of the procedure is to obtain a repetition that matches the text verbatim without the use of non-speechrelated cues such as gestures (De Filippo \& Scott, 1978). Tracking performance is quantified and scored in terms of the number of words transmitted per minute (wpm).

This procedure can be differentiated from traditional approaches to speechreading testing on the following grounds:

1) It comprises a discourse task and therefore ongoing "meaningful speech" (and not isolated, single-word stimuli.) is employed.

2) It can be described as interactive in nature. Since the procedure utilises a dyad and the talker's behaviour depends on the speechreader's performance, the interactive dyna mics of a real conversation are allowed to play an important role in the evaluation.

3) 'I'he scoring deviates drastically from conventional procedures in that the typically "all or nothing" approach to sentence scoring is not employed; rather, scoring results is a rate measure (al though as a prerequisite a $100 \%$ accuracy is implied.)

4) The final wpm score relates to communication efficiency and, as such, represents a composite measure of communication rase. 'Iherefore, in contrast with traditional measures, the wprn score reflects all the components within the communication interaction, namely the transmission, processing and correction as well as response time. In fact, De Filippo and Scott (1978) have suggested that this task not only taps perceptual skills (and the accuracy thereof), but a combination of an individual's perceptual and communicative abilities.

Since the tracking technique's inception, it has been used with individuals of all ages and with a number of modifications for multiple purposes (Owens \& Raggio, 1987; Osberger, Johnson \& Miller, 1987). As mentioned previously, its most extensive use has been in studies documenting changes in communication efficiency as a result of sensory devices (Cowan, Alcanta, Blamey \& Clark, 1988; De Filippo \& Scott, 1978; Sparks et al. 1979; Müller, 1988). In addition, a number of studies (e.g. Danz \& Binnie, 1983; I esner \& Kricos, 1987) have demonstrated its feasibility for intervention and training purposes. For the purpose of this article, discussions will be limited to the use of speech tracking with adults.

\section{APPEAL OF THE SPEECH TRACKING PROCFDURF,}

Since tracking is a live-voice procedure, it can be easily administered without the use of any equipment. In addition, it allows for quantification of the efficacy of the communication process. The procedure requires a different passage to be used at each session and the refore any learning of the test material is prevented. In view of the fact that ongoing speech is used in an interactive manner, "real-life" conditions are more closely approximated with use of the CDT technique; the task is therefore known for its high face validity (Levitt, Waltzman, Shapiro \& Cohen, 1986).

As with many of the tracking method's predecessors, the development of this procedure seems to have arisen from clinical necessity. In retrospect, it is speculated that perhaps one of the major motivations for its development revolved around the aspect of repeated presentations. It seemed that the typical practice effects associated with perceptual tasks could be bypassed by means of this new technique. Although difficulties associated with traditional speechreading tests have to some extent been overcome by the speech tracking procedure and while other problematic issues are shared by conventional methods of speech recognition testing, it has now become apparent that this new procedure has introduced different sources of variability, which have often been disregarded by the clinical and research communities (for example, Hopkinson et al. 1986).

These methodological issues appear to contra-indicate the use of tracking for purposes of evaluation and in research investigations employing an across-subject design(I.esner, I,ynn \& Brainard, 1988). A recent position paper by Tye-Murray and Tyler (1988) has been the first to review and identify formally the confounding variables specific to this technique. In addition, in order to minimize the shortcomings associated with the use of this test instrument, these authors have proposed stringent guidelines for within-subject testing.

\section{CRITICISMS DIRECTED AT CONTINUOUS DISCOURSE TRACKING AS A TEST PROCEDURE}

The overall concern regardirig the use of tracking as a test instrument pertains to one major aspect, namely that the ultimate score achieved by a receiver will vary as a function of several extraneous variables. Tye-Murray \& Tyler (1988) maintain that these variables are almost impossible to control. As mentioned before, many of the problems associated with tracking as a test procedure are also relevant to the use of sentence-list speechreading tests. In their opinion, however, there are unique shortcomings specific to the use of the tracking task. This has led these authors to conclude that the speech tracking procedure "does not reliably measure a receiver's ability to recognize speech" (Tye-Murray \& Tyler, 1988, p. 227). In contrast De Filippo (1988) has argued that "for evaluating speechreading performance tracking requires careful attention to the (very) same issues of assessment as any other 
(speechreading) technique" (emphases added) (p. 230).

Hence, the purpose of the following discussion is firstly, to summarise the main variables and issues of concern faced by the clinician-researcher when employing the CDT procedure for evaluative purposes. Particular emphasis is given to textrelated variables, since a review of the literature reveals an urgent need to give priority attention to issues underlying this aspect. Secondly, in response to Tye-Murray and Iyler's (1988) critique, this article endeavours to address some fundamental theoretical issues arising from their comments and to delineate a reas awaiting further exploration. Such investigations are deemed essential, before the CDT technique is either prematurely discarded or restricted in terms of its potential usefulness as an assessment tool.

Table 1: Summary of sources of error associated with the CDT task

\author{
SENDER (S) VARIABLES: \\ Rapport and familiarity with receiver ( $R$ ) \\ Ss' different testing/interaction styles \\ Ss' personal attributes: visual intelligibility, clarity of \\ Sender bias \\ speech production etc. \\ Change of S characteristics over time \\ Variations in $\mathrm{S}$ presentation across conditions

\section{RECEIVER ( $\mathrm{R}$ ) VARIABLES:} \\ Degree of familiarity with $\mathrm{S}$ \\ Speech intelligibility and language proficiency \\ Ability to utilise contextual cues \\ Interactions between $\mathrm{Rs}$ and text material \\ Cognitive abilities (e.g. memory) \\ Age variables \\ Learning and adaptation effects \\ Differences in nonsensory factors: motivation, $\mathrm{R}$ bias
}

\section{TEAM VARIABLES:}

Strategy used across conditions

Efficiency in probing/use of repair strategies

\section{TEXT VARIABLES:}

T'ext complexity

Literary style (dialogue vs descriptive vs narrative)

Ease of segmenting text

Level of familiarity/difficulty throughout text

Socio-cultural relevance

Resemblance to the spoken idiom

Source of material

Booklength material: R's ability to exploit story plot, R's familiarity with characters

Passage equivalence: across conditions, devices and R's; method whereby determined

\section{SCORING VARIABLES:}

Type of scor ing system

Method used in interpretation of scores

Manner whereby missed words are accounted for
'Ihe application of the CI'T' procedure to the test situation gives rise to the issues of uncontrolled sender and receiver characteristics as well as confounding text characteristics. In addition, a variety of scoring schemes have been proposed some with the precise aim of statistically controlling the sources of variability. Iable 1 provides an overview of confounding variables associated with the use of tracking as a test procedure as identified and described in some of the most recent publications (Tye-Murray \& Tyler, 1988; De Filippo, 1988; Lesner, Lynn et al. 1988; Montgomery \& Demorest, 1988). Proposed solutions for minimizing these effects are summarized in T'able 2.

Table 2: Summary of strategies which may reduce error on the CDT task

\section{FOR SENDER (S) VARIABLES:}

Use a variety of senders (Ss)

Probe the effects of different senders

Train Ss before data collection

Define the Ss' rules

Provide sources of external validation

Computerise the speech tracking task

Keep S blind to the test condition

Monitor S externally

Use same $S$ across conditions

\section{FOR RECEIVER (R) VARIABLES:}

Provide orientation to the tracking task

Provide pre-training practice

Specify the repair strategies

Ensure that R ( $s$ ) follow precise pattern of

responding

Insist on verbatim responses

Include a last-resort repair strategy

"Normalise" the tracking scores

Probe suspect nonsensory effects

FOR TEAM VARIABLES:

Provide both partners with orientation and practice

\section{FOR TEXT VARIABLES:}

Use of different text source each session?

Use of controlled materials

Ave rage performance over a large sample of text/time

Predetermine passage equivalence

Determine text equivalence by:

subjective ratings of passages by a panel

ranking of texts based on scores of good speech-

readers

grading of selected texts

\section{FOR SCORING VARIABLES:}

Use wpm scores only for within-subject comparison

Reduce some sources of error by use of scoring systems

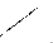

Account for missed words by adopting a penalty scheme or limiting the correction time 


\section{SENDER VARIABLES}

As reflected in 'Table 1, the sources of talker variability constitute one of the major obstacles to the collection of reliable and valid assessments. Although recent developments in computer-assisted tracking such as CASPER (Boothroyd, 1987 cited by Ie Filippo, 1988) and CAST (Fuller \& Cicchelli, 1986 cited by Sims, 1988) offer a potential solution in terms of controlling talker variables; it will be at the cost of restricting interactions with the receiver and limiting tracking as a test procedure to well-equipped centres. However, in the light of mounting criticisms of the use of tracking as a test, computerisation of the CD'T technique for evaluative purposes may eventually become universal.

It follows that until such time and until further more specific information regarding the differential effects of the various sender variables becomes available, clinicians and researchers will need to take the necessary steps to ensure adlequate talker training. In fact, the implementation of the suggestions provided in the literature can be viewed as a pre-requisite for generating data of at least minimal accuracy and borderline reliability. In addition, as highlighted by the study of Sparks et al. (1979), it remains the obligation of the experimenter/ clinician to explore particular sender effects, for instance talker bias, whenever this becomes suspect.

\section{RECEIVER VARIABLES}

Many receiver-related confounding variables do not appear to be unique to tracking. Nonsensory factors such as reluctance to guess, motivation, level of attention and alertness also operate when other speech recognition tests are employed, although it is apparent that some speechreader characteristics (day-to-day variability over time, the receiver's learning curve of the tracking task per se) specifically pertain to tracking.

As suggested by Montgomery and Demorest (1988) nonsensory effects are an important area for research, requiring specialised research designs and new methods of testing speech recognition. In the meantime the diagnostician who strives to increase her/his accountability in clinical practice will stand tó benefit from allocating sufficient time to incorporate De Filippo's (1988) proposed sets of activities which are aimed at reducing the effects associated with receiver task learning. Furthermore, by ensuring optimal test conditions and replicating conditions, one can minimise the influence of short term maturational effects.

\section{TEXT VARIABLES}

The most neglected area in terms of speechreading assessment in general concerns the issues of test construction and evaluation. These inadequacies are also apparent when it comes to the tracking method. It is clear that no standardised or extensively researched text materials are available for use with CDT and investigators employ a variety of connected discourse materials selected from a wide range of sources. Furthermore: there are variations in the degree to which such materials have been adapted and subjected to preliminary investigations. An unfortunate trend which has been noted is that investigators seem to prefer the selection of new "untested" materials. rather than subjecting existing text material to further refinements before administration to their subjects.

In terms of material selection and text composition. it is evi- dent that only arbitrary guidelines and loosely defined criteria appear to be available in the Audiology literature. The urgent need for rigorous studies in crder to find the optimum length, type, and linguistic difficulty of tracking materials has been echoed by researchers such as Lesner \& Kricos (1987) and Matthies \& Carney (1988). Perhaps by borrowing from recent interdisciplinary research in the study of connected discourse (e.g. Ulatowska et al. 1983; Van Dijk \& Kintsch, 1978) audiologists could establish more objective methods for indexing the complexity and structure of the various types of discourse materials. This would be a promising first step in generating more specific and academically sound criteria for the construction of text materials. Another factor often ignored by therapists using the CI'T' technique, but of considerable importance in terms of the South African context, is the selection of culturally appropriate test stimuli.

A practice which appears to characterise existing "try-out" procedures during the test development and evaluation stage of the tracking task involves the reliance on subjective and rather superficial methods of determining the suitability of the material. As borne out by the studies of Lesner and Kricos (1987) and Lesner et al. (1988), the piloting of text material on a few normal hearing college students does not guarantee suitability of the text stimuli - particularly when tracking is performed with the geriatric population. Nor does rating by a panel of judges alone ensure enterpassage equivalence. It follows that the application of more large-scale and thorough methods to determine the suitability of text materials is indicated and this area should become a research priority.

The provision of psychometric data for any newly constructed test is a recurrent theme in the research literature on Speech Pathology and Audiology. Ventry \& Schiavetti (1980) make the point that many researchers fail to realise that the concept of reliability and its assessment also applies to measurements made by those who develop their own measuring material. It is generally agreed that extra time should be spent by such researchers (as well as test users) in examining the instruments' reliability before reporting on their use.

In terms of the tracking task itself(and the material employed), test evaluation is urgently required in order to examine systematically the various facets of reliability, inter-passage equivalence, susceptibility to practice, talker influences, etc. By calibrating the CDT procedure on a large representative sample and analysing the data psychometrically utilising the present statistical theories applicable to speechreading instruments (Montgomery \& Demorest, 1988), more concrete documentation regarding the performance of hearing-impaired individuals on the tracking task could be obtained.

In accordance with the main focus of this paper, namely, the need for systematic research into the suitability of text materials, the authors propose that a small sample of passages is initially selected for investigation and that this sample is:

1) rated for similarity by expert judges;

2) assessed for equivalence in the reading speed (wpm) of senders using a repeated measures design with control of order effects;

3) assessed for equivalence of comprehensibility by normal hearing agegraded receivers;

4) assessed for equivalence in CDT wpm rates using normal hearing receivers and the same type of design advocated in (2); 
5) used to establish norms in terms of the average wpm rates of agegraded normal hearing receivers; and

6) assessed for text equivalence by using number of errors as the criterion measure. In terms of this requirement the same person should make the same number of errors on each text.

In addition, test-retest reliability in the form of correlations (per text) of the wpm performance data can be computed. In this case test-retest intervals must be large enough to counter the effects of memory and text learning but short enough to avoid maturational influences.

\section{METHODS OF SCORING}

One of the major issues faced by test developers interested in speechreading performance concerns the important and rather arbitrary decision-making required in the selection of a final scoring system. In tracking, no universal scoring procedure exists and this further complicates the interpretation of tracking performance across studies.

It is uniformly agreed that absolute wpm scores have little meaning on their own, except perhaps in within-subject comparisons. As discussed in the literature, expressing performance in terms of relative gain, although meaningful, can be quite misleading if reported only in terms of gain. Chemal (1989) and De Filippo(1988) point out the differences in functional communication skills between the following two individuals:

a) Speechreader A who has changed tracking rate from 10-20 wpm and $B$ who has increased from 45-90 wpm. Although both individuals claim a $100 \%$ gain (by doubling their scores), the difference in functional communication between individual $\mathrm{A}$ and $\mathrm{B}$ are considerable.

b) Speechreader A who demonstrates a 10 wpm gain in tracking rate (improvement from $20-30 \mathrm{wpm}$ ) and $B$ who also demonstrates a relative gain of $10 \mathrm{wpm}$ by increasing his/ her scores from 90-100 wpm. Again, the differences in functional skills between the two receivers are clear, despite the uniform increments in tracking rates.

A number of modifications to the calculation of the wpm scores which minimise the influence of some sources of variability have been suggested in the literature. Until a uniformscheme has been adopted, however, it would appear essential for the clinician-researcher to heed the following statement (De Filippo, 1988, p. 299):

"Scoring should be accomplished by strict adherence to whatever rule system is constructed for both talker and speechreader, with consistency in its application, adjustment of the final wpm score to account for missed words and inclusion of sufficient data in each score reported."

\section{DISCUSSION}

Despite the apparent simplicity of the procedure, clinical experience with tracking and preliminary investigations of this method have established that speech tracking is not straightforward. In fact, a number of issues need to be fully appreciated in order to avoid the many pitfalls inherent in its application.

In the experience of the first author, the implementation of the multitude of precautions cited in the literature (in order to reduce possible contamination of tracking data) has certain negative effects. The clinician in order to adhere to all the "rules" (in an attempt to approximate laboratory conditions), tends to become a "testing robot" and some of the original appeal of the tracking method is thereby lost. In such circumstances, the clinician who assesses client performance may well be tempted to hand over the task of evaluation to high technology instruments. This problem which reflects the fine balance which exists between internal validity (control) and external validity(generalisability) is well recognized in experimental methodology (Kerlinger, 1983) and explains why any effort to increase control is likely to coincide with a decrease in external validity.

In view of the above, future research which differentiates between "critical" and "negligible" extraneous variables affecting tracking performance would seem to be of paramount importance. It is evident that although previous research has suggested many potentially important factors influencing tracking performance, formal studies exploring their relative effects are seriously lacking. By examining the magnitude of potentially confounding variables (and not only the presence or absence thereof), the clinician-researcher is likely to be in a better position to identify and control the essential sources of variability. In addition, the problems associated with "over-control" will probably be greatly reduced.

Future studies employing single-subject designs may offer a suitable evaluation technique for exploring experimentally the extent of sender effects (i.e. sender maturation) and for manipulating sender characteristic such as talker bias. Of equal importance is the reduplication of studies in order to systematically accumulate a substantial body of data which will assist in differentiating between "significant" and "insignificant" variables. However, any research applications of the tracking technique are likely to be severely restricted, until further studies into the establishment of equivalent passages and appropriate methods for determining passage equivalence are undertaken.

It is felt that speech therapists/audiologists have much to contribute to the area of test development and evaluation. Inter disciplinary efforts such as those evident in the development of sophisticated hearing handicap scales (Demorest \& Erdman, 1987) have increased our professional confidence in both diagnosis and the specification of treatment strategies and have enhanced our credibility as members of an essential profession.

In an attempt to address the need for more suitable local tracking materials for assessment purposes, the first author compiled twenty sets of controlled text passages. A detailed account of the methodology used in the development of the material is beyond the scope of this article. It suffices to report that the available literature guidelines were employed in the construction of the material and modifications to the test passages were performed as a result of subjective ratings on a number of criteria by two independent speech therapists/ audiologists. Evaluation of a small sample of selected tex́ts has been initiated and is continuing.

\section{CONCLUSION}

The foregoing discussion highlighted the need to establish research priorities in terms of future investigations pertaining 
to the tracking procedure. Furthermore, specific recommendations in this regard were proposed. At the same time, it seems rather unrealistic to require that one particular measurement tool should be entirely adequate to account for the multiple dimensions underlying the study of speech information processing during face-to-face communication. Tracking is a function of a specified message and channel and takes place in a specific environment. The resultant tracking score globally, if imprecise, reflects the combination and interaction of all these components as they relate to a single context. In fact, the advantage of for instance, Garstecki's (1981) assessment scheme is that it permits systematic sampling of auditory-visual speech perception performance over a much broader continuum.

Finally, it must be remembered that the present criticisms directed at the CDT procedure reflect much of a cause-effect theoretical framework in terms of research methodology. New paradigms particularly in the field of psychology (e.g. Buss \& Cantor, 1989) are emerging with the emphasis on interactive assessment and evaluation of the adaptive functioning of the individual in terms of real-life demands. Ross (1988) for example, refers to the eco-psychological approach in the assessment of the behaviour of deaf individuals which has emerged in response to growing disenchantment with traditional personality tests. In the area of evaluating speechreading and communicative functioning of the hearing-impaired adult, the adoption of such a paradigm would appear to have the potential of providing the clinician with functional measures of appraisal which, in conjunction with the use of formalized methods, could ultimately contribute to a more integrated diagnosis and balanced theoretical perspective.

\section{ACKNOWLEDGEMENTS}

This paper is dedicated to the late Mrs Evelyn Vermaak whose active participation in therapy greatly enhanced the clinical perspective of this article. The writers gratefully acknowledge the support of the following persons during the preparation of this manuscript: Professor 'C Penn (Head, Department of Speech Pathology and Audiology, University of the Witwatersrand), Alida Müller, Eleanor Ross, Denise Anderson, Sue Sherrat and Heila Jordaan.

\section{REFERENCES}

Bürs, D.M. and Cantor; N. Personality Psychology: Recent Trends and Emerging Directions. Springer-Verlag. New York, 1989.

Chemal, C. Personal Communication. (Fx) Senior Research Specialist. NIPR, Johannesburg, 1989.

Cowan, R.S.C., Alcanta, J.I., Blamey, P.J. and Clark, G.M. Preliminary evaluation of a multichannel electrotactile speech processor. Juurnal of the Acoustical Society of America, 83, 2328-2338, 1988.
Cronin, B. The DAVID system: The development of an interactive video system at the National Technical Institute for the Deaf. American Annals of the Deaf, 124, 616-618,1979.

Danz, A.D. and Binnie, C.A. Quantification of the effects of training the auditory-visual reception of connected speech. Ear and Hearing, 4, 146-151, 1983.

De Filippo, C.I. Tracking for speechreading training. In De Filippo, C.L. \& Sims. D.G. (Eds.) New Reflections on Specthreading. The Volta Review, 90, 215-236, 1988.

De Filippo, C.L. \& Scott, B.L. A method for training and evaluating the reception of ongoing specch. Journal of the Acoustical Societu of America, 63, 1186-1192, 1978.

Demorest, M.E. and Erdman, S.A. Development of the Communication Profile for the hearing-impaired. Journal of Speech and Hearing Disorders, 52, 129-143, 1987.

Garstecki, D.C. Auditory-visual training paradigm for hearingimpaired adults. Journal of the Academ y of Rehabilitative Audiologf $14,223-238,1981$

Hopkinson, N.T., McFarland, W.H., Owens, E., Reed, C., Shallop, J., 'Tillman, 'T., Tyler, R.S. and Williams, P.S. Report of the Ad Hoc Committee on Cochlear Implants, Asha, 28, 29-52, 1986

Kerlinger, F.N. Foundations of Behavioural Research. Holt-Saunders, New York, 1983.

Lesner,S.A. and Kricos, P.B. 'T'racking as a communication enhancement strategy with nursing home residents. Journal of the Academu of Rehabilitative Audiologu, 20, 39-48, 1987.

I esner, S.A., I.ynn, J.M. and Brainard, J. Feasibility of using a singlesubject design for continuous discourse tracking measurement. Journal of the Academy of Rehabilitative Audiology, 21, 83-89, 1988.

I evitt, H. Waltz.man, S.B., Shapiro, W.H. and Cohen, L. Evaluation of a cochlear prosthesis using connected discourse tracking. Journal of Rehabilitation Research and Development, 23, 147-154, 1985.

Massaro, D.W. Spech Perception by Ear and Eyf: A Paradigm for Psychological Inquiry. Erlbaum, Hillsdale, New Jersey, 1987.

Matthies, M.L. and Carney, A.E. A modified speech tracking proccdure as a communicative performance measure. Journal of Spech and Hearing Research, 31, 394-404, 1988.

Middelweerd, M.J. and Plomp, R. The effect of speechreading on the speech reception threshold of sentences in noise. Journal of the Acoustical Society of America, 82, 2145-2147, 1987.

Montgomery, A.A. and Demorest, M.E. Issues and developments in the evaluation of speechreading. In De Filippo, C.L. and Sims, D.G. (Eds.) New Reflections on Speechreuding. The Volta Review, $90,1988$.

Müller, A.M.U. Multichannel cochlear implant program at Tygerbers Hospital. Procectings of the Audiolory Congress. South African Speech and Hearing Association, Cape Town, 1988.

Osberger, M.J., Johnson, D.L. and Miller, J.D. Use of connected discourse tracking to train functional speech skills. Ear and Hear ing, 8, 31-36, 1987 .

Owens, E. and Raggio, M. The UCSF tracking procedure for evaluation and training of speech reception by hearing-impaired adults. Journal of Speech and Hearing Disorders, 52, 120-128, 1987.

Ross, E. The implications of applying empirical research with deaf communities. Welfure Focus, 23(2), 8-12, Dec. 1988

Sims, D.G. Video Methods for Specchreading Instruction. In De Filippo, C.L. \& Sims, D.G. (Eds.) New Reflections on Speechreading. The Volta Review, 90, 1988.

Sparks, D.W., Ardell, L.A., Bourgeois, M., Wiedmer, B. and Kuhl, P.K. Investigating the MFSA: 'The transmission of connected discourse. Journal of the Acoustical Societu of America. 65,810 815,1979 .

Tye-Murray, N. and Tyler, R.S. A critique of continuous discourse tracking as a test procedure. Journal of Speech and Hearing Disorders. 53, 226-231, 1988 .

Ulatowska, H.K., Freedruan-Stern, R., Doyel, A.W. MacalusoHaynes, S. and North, A.J. Production of Narrative Discourse in Aphasia. Brain and Language, 19, 317-334, 1983.

Van Dijk, 'T.A. and Kintsch, W. Cognitive psychology and discourse in recalling and summarizing stories. In Dressler, W.U. (Ed.) Current Trends in Text Linguistics. De Gruyter, New York, 1978 .

Ventry, I.M. and Schiavetti, N. Fivaluating Research in Speech Pathologu and Audiology. Addison-Wesley, Menlo Park, California, 1980 . 
The acoustic advantages of In-The-Canal hearing aids are well known. However, until now their use has been limited by acoustic feedback which causes oscillation (whistling). Acoustimed has developed a technique for controlling the phase response of hearing aids to prevent oscillation. Full details are a trade secret but results are spectacular.

We can now make In-The-Canal hearing aids that have more USABLE gain than Behind-The-Ear models and they do not oscillate regardless of how large we make the vent. With the Phantom Model AFP (power) version it is possible to correct nerve deafness with high frequency loss as great as $90 \mathrm{~dB}$.

The Phantom Models AF and AFP have a simple but effective noise control. When the volume is turned down low frequency noise is reduced more than the essential high frequencies. This unique feature has the effect of improving the signal-to-noise ratio in noisy conditions.

Because of the microphone position Phantom hearing aids have better high frequency performance than Behind-The-Ear models and since there is no tubing they are more efficient and have a smoother frequency respinse. Previously ln-The-Canal hearing aids could be used only for mild hearing loss due to feedback problems. With the new Phantom hearing aids there are LESS feedback problems than with Behind-The-Ear models. This allows us to make Phantom aids which work better than many Behind-The-Ear $\mathrm{PP}$ hearing aids.

Phantom hearing aids are made in 3 basic models. The approximate fitting range is illistrated in this diagram. Performance is controlled by transducer selection.

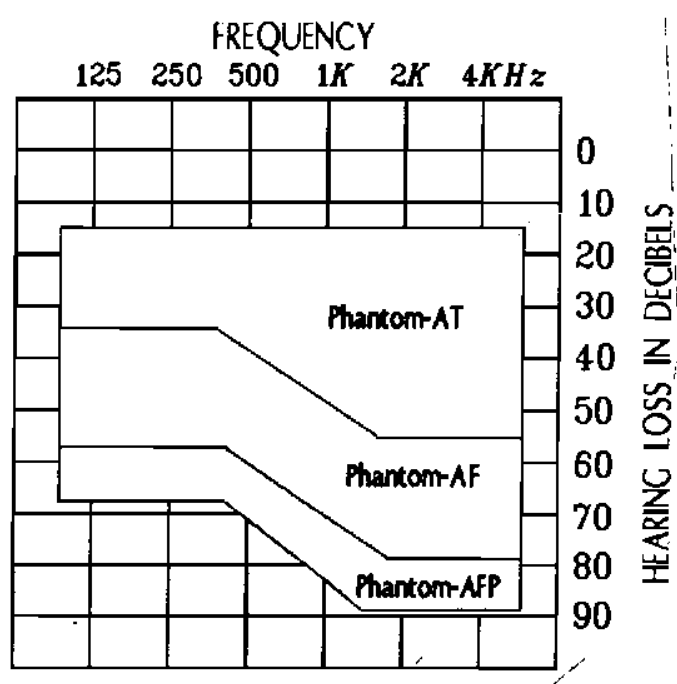

ACOUSTIMED HEARING SERVICES

327 Bosman Building

Cor. Eloff and Bree Streets, Johannesburg

Tel: (J11) 337-2977 